\title{
Konya Bölgesinde Gastroskopi Yapılan Hastalarda Histopatolojik Bulgular ve Helicobacter Pylori Sıklığı
}

\author{
${ }^{1}$ Hüseyin Korkmaz, ${ }^{2}$ Onur Kerpiç, ${ }^{3}$ Tuncer Temel \\ ${ }^{1}$ Selçuk Üniversitesi Tıp Fakültesi, İç Hastalıkları ABD. Gastroenteroloji BD. Konya \\ ${ }^{2}$ Selçuk Üniversitesi Tıp Fakültesi, Gastroenteroloji Endoskopi Ünitesi. Konya \\ ${ }^{3}$ Eskişehir Osmangazi Üniversitesi Tıp Fakültesi, İç Hastalıkları ABD. Gastroenteroloji \\ BD. Eskişehir \\ e-posta: husein68@hotmail.com
}

\begin{abstract}
ÖZET: Çalışmanın amacı Helicobacter pylori (H. pylori) sıklığı, sıklığın yaş, cinsiyet ve histolojik bulgularla ilişkisinin araştırılmasıdır. Gereç ve yöntem: Ocak 2012- Haziran 2013 döneminde, endoskopi ünitesinde herhangi bir nedenle gastroskopi yapılan ve antrum-korpus biyopsisi alınan hastalar geriye dönük olarak incelendi. H. pylori sıklığı genel, cinsiyet ve yaş gruplarına ayrılarak belirlendi. Bulgular: Çalışmaya alınan hastanın ortalama yaşı $49.3 \pm 16.5$ idi. Hastaların 1057'si (\%57.7) kadın olup yaş ortalaması $48.3 \pm 16.1$ iken 777'si (\%42.2) erkek olup yaş ortalaması 50.1 \pm 17.0 idi. H. pylori $1099(\% 60.1)$ hastada negatif iken, 314 erkek (\%40.41) ve 416 kadın (\%39.13) olarak toplam 730 (\%39.9) hastada pozitif bulundu. Kadın ve erkeklerde H. pylori sıklı̆̆ benzerdi. H. pylori pozitifliği hastaların \%57'inde hafif, \%30'unda orta, \%13'ünde ağır şiddetteydi. 14-30 yaş, 31-45 yaş, 46-60 yaş ve 61-95 yaş gruplarında $H$. pylori sıklığı sırasıyla $\% 49.8, \% 45.7, \% 38.5, \% 29.7$ idi. 45 yaş altı hastalarda H. pylori sıklığı anlamlı derecede yüksek bulundu $(\mathrm{p}=0.001)$. Histotopalojik incelemede, nonatrofik gastrit, atrofik gastrit, intestinal metaplazi ve normal histoloji gözlenen hastalarda $H$. Pylori sıklığı sirasıyla \%47.8, \% 40.7, \% 27.0, \% 18.5 ve \% 6.1 idi. Sonuç: Konya bölgesinde H.pylori s1klı̆̆ $\% 39,9$ ' olup cinsiyetler arasında anlamlı fark yokken 45 ve altı yaş hastalarda H.pylori sıklığı anlamlı derecede yüksek bulundu $(\mathrm{p}=0.001)$.
\end{abstract}

ANAHTAR KELIMELER: Üst gastrointestinal endoskopi, Helicobacter pylori, prevelans, histopatoloji.

ABSTRACT: The aim of this study is to investigate the prevelance of Helicobacter Pylori $(H$. pylori), the relationship between helicobacter pylori prevelance and age-gender-histo-pathological findings. Material and Methods: Data of the patients, whom gastroscopy was performed between January 2012 - June 2013 secondary to any occasion and biopsy specimens were obtained from antrum-corpus, were investigated retrospectively. H. Pylori prevelance was determined at general patient group and subgroups which were allocated according to gender and age intervals. Results: Mean age of the patients was $49.3 \pm 16.5$. While $1057(57.7 \%)$ of the patients were female with a mean age of $48.3 \pm 16.1,777$ of the patients were male (42.2\%) with a mean age of 50.1 \pm 17.0 . Although H. Pylori was negative at $1099(60.1 \%)$ of the patients, it was positive at $730(39.9 \%)$ of the patients, 314 male $(40.41 \%)$ and 416 female $(39.13 \%)$. H. Pylori prevelance was similar at both genders. Positivity of $\mathrm{H}$. Pylori was mild at $57 \%$, moderate at $30 \%$ and severe at $13 \%$ of the patients. At age allocated subgroups; $H$. Pylori positivity was $49.8 \%, 45.7 \%, 38.5 \%, 29.7 \%$ respectively at patients between 14-30, 31-45, 46-60 and 61-95 ages. Prevelance of H. Pylori was significantly higher at patients below the age of $45(\mathrm{p}=0.001)$. H. Pylori positivity was $47.8 \%$, $40.7 \%, 27.0 \%, 18.5 \%$ and $6.1 \%$ respectively at patients with histo-pathological diagnosis of nonatrophic gastritis, atrophic gastritis, intestinal metaplasia and normal histology. Conclusion: $H$. Pylori prevelance is $39.9 \%$ at patients from Konya region, prevelance is similar at both genders, prevelance of $\mathrm{H}$. Pylori is statistically significant at patients below the age of 45 .

KEY WORDS: Upper gastrointestinal tract endoscopy, Helicobacter Pylori, prevelance, histopathology. 


\section{Giriş}

Helicobacter pylori (H. pylori), 1983 de ilk defa bilim dünyasına tanıtıldığından bu yana; gastrit, tekrarlayan gastrik ve duoedenal ülser, fonksiyonel dispepsi, gastrik kanser ve MALT lenfomasına neden olduğu kanıtlanmış, gram negatif, mikroaerofilik, spiral şekilli ve hareketli bir mikroorganizmadır (1). Dünya nüfusunun \% 50-90'1nın bu patojen mikroorganizma ile enfekte olduğu tahmin edilmekte ve mikroorganizmanın çocukluk yaş gurubunda vücuda alındığ 1 düşünülmektedir $\quad(2,3)$. Gelişmiş ülkelerdeki $H$. pylori prevalansı, çocukluk yaş grubunda $\% 0-5$ ve yetişkinlerde $\% 30$ 50 oranlarında rapor edilmektedir $(4,5)$. Ülkemizin de yer aldığı gelişmekte olan ülkelerde

H. pylori prevelansı ise çocukluk yaş grubunda \% 60-70 ve yetişkinlerde \% 8590 olarak bildirilmektedir $(3,6,7)$. $H$. pylori'nin bulaşma yolları kesin olarak bilinmemekle birlikte mikroorganizmanın vücuda girişi açısından kalabalık ortamda yaşama, kötü hijyen koşulları, düşük sosyoekonomik düzey, kötü beslenme, demir eksikliği anemisi, koroner kalp hastalığı, $\mathrm{O}$ kan grubunda olma ve annenin eğitim düzeyinin düşük olması risk faktörleri olarak kabul edilmektedir $(3,5)$. Özellikle kalabalık ortamlarda ve kötü hijyen koşullarında yaşayanlarda $H$. pylori enfeksiyonunun daha s1k görülmesi fekal-oral yolla bulaş ihtimalini desteklemektedir (5).H. pylori'nin tanısı için en değerli yöntem (altın standart) gastroskopik biyopsi ile alınan örneklerden yapılan histopatolojik incelemeler ve kültür ile bakterinin gösterilmesidir (8,9). Histopatolojik incelemede, çeşitli boyama teknikleri arasında hem hemotoksilen-eosin, hem de modifiye giemsa hassas ve kolay olduğu için tercih edilmektedir (10). Ayrıca, tanıda polimeraz zincir reaksiyonu (PCR) ve hızlı üreaz testleri gibi diğer invaziv metotların yanı sıra üre nefes testi (ÜNT), serolojik testler ve H.pylori dışkı antijen (HpDA) testi gibi non-invaziv yöntemlerde kullanılmaktadır $(8,9)$. Bu çalışmada, çeşitli nedenlerle Konya Selçuk Üniversitesi Tip Fakültesi Hastanesi'ne başvuran ve üst gastrointestinal sistem (GISS) endoskopisi yapılan hastalarda endoskopik bulguların dağglımı ve alınan endoskopik antrumkorpus biyopsi örneklerinde $\mathrm{H}$. pylori sıklığı ve sıklığın yaş ve cinsiyet ile ilişkisinin araştırılması amaçlandı.

\section{Gereç ve Yöntem}

Ocak 2012 - Haziran 2013 tarihleri arasında Konya Selçuk Üniversitesi, Tıp Fakültesi, Gastroenteroloji Bilim Dalında herhangi bir nedenle üst GİS endoskopisi yapılan ve antrum-korpus biyopsisi alınan hastalar geriye dönük olarak incelendi. Özofagus, $\mathrm{Z}$ çizgisi, kardia, fundus, korpus, antrum, pilor, bulbus ve duodenum ikinci kısmına ait yeterli bilgi içermeyen ve antrum-korpus biyopsi örneği olmayan raporlar değerlendirmeye alınmadı. Endoskopik işlemleri aynı gastroenterolog tarafindan ve Olympus CV-180 videoendoskoplar (Japan) kullanılarak yapılan toplam 1829 hasta çalışmaya dahil edildi. Hastaların yaş, cinsiyet ve başvuru yakınmaları kayıt edildi. H. pylori ve histopatolojik tanı için antrum-korpusdan alınan biyopsi preparatlar1 hemotoksilen-eosin ve modifiye giemsa ile boyanarak 1 şı mikroskopisinde incelendiği ve preparatlardaki bakteri yoğunluğunda göre $(+)$ hafif, $(++)$ orta, $(+++)$ şiddetli pozitif olarak raporlandığ1 saptand1 $(\mathrm{H} 2)$. Tüm hasta grubundaki H. Pylori sıklığı ile yaş ve cinsiyete göre $H$. pylori prevelans1 araştırıldi.

\section{İstatistiksel Analiz}

$\mathrm{Bu}$ çalışmada sürekli normal dağılım gösteren değişkenler için t testi ile analiz edildi ve ortalama \pm standart sapma 
(ort \pm ss) olarak gösterildi. Kategorik değişkenler için kikare analizi yapıldı ve frekans ve yüzde şeklinde gösterildi. İstatistiksel önemlilik için $p<0.05$ değeri kabul edildi. İstatistiksel analizler için IBM SPSS Statistics 15.0 (SPSS Inc., Chicago, Illinois) programı kullanıldı.

\section{Bulgular ve Analizler}

Çalışmaya alınan 1829 hastanın ortalama yaş1 $49.3 \pm 16.5$ idi. Hastaların 1057'si (\%57.7) kadın olup yaş ortalaması $48.3 \pm$ 16.1 iken 772si (\%42.2) erkek olup yaş ortalamas1 $50.1 \pm 17,0$ idi. H. pylori 1099 (\%60.1) hastada negatif iken, 314'ü erkek (\%40.41) ve 416's1 kadın (\%39.13) toplam 730 (\%39.9) hastada pozitifti. Kadın ve erkekler hastalar arasında $H$. pylori sıklıkları açısından istatistiksel anlamlı bir fark gözlenmedi ( $\mathrm{p}>0.05)$. H. pylori pozitif saptanan hastaların \%57'inde hafif, \%30'unda orta, \%13'ünde ağır şiddette pozitiflik rapor edildi. $H$. pylori pozitifliği yaş gruplarına göre incelendiğinde; 14-30 yaş, 31-45 yaş, 46-60 yaş ve 61-95 yaş gruplarında $H$. pylori siklığı sirasıyla 143/287 (\%49.8), 212/463 (\%45.7), 235/609 (\%38.5), 140/470 (\%29.7) idi (Tablo 1). 14-30 yaş grubunda $H$. pylori sıklığı en yüksek ve 61-95 yaş grubunda en düşük olarak bulundu. 14-30 yaş ile 3145 yaş grupları ve 46-60 ile 61-95 yaş grupları arasında $H$. pylori sıklığ1 bakımından istatistiksel anlamlı bir fark bulunamadı. Fakat yaş grupları dağılımına göre 45 yaş altı hastalarda, 45 yaş üstü hastalara göre $H$. pylori sıklığ 1 istatistiksel olarak anlamlı derecede yüksek bulundu $(\mathrm{p}=0.001)$. Histotopalojik incelemede, nonatrofik gastrit, atrofik gastrit, intestinal metaplazi ve normal histoloji gözlenen hastalarda $H$. pylori siklığı sirasıyla $\% 47.8, \% \quad 40.7, \% 27.0, \% 18.5$ ve $\% 6.1$ olarak saptand 1 (Tablo 1).

Tablo 1

Yaş gruplarına ve histolojik bulgulara göre Helicobacter pylori sıklıkları

\begin{tabular}{lccc}
\hline Değişkenler & $\begin{array}{c}\text { Toplam } \\
\mathbf{n}(\%)\end{array}$ & $\begin{array}{c}\text { H.P (+) } \\
\mathbf{n}(\%)\end{array}$ & $\begin{array}{c}\text { H.P (-) } \\
\mathbf{n}(\%)\end{array}$ \\
\hline Yaş grupları & & & \\
$14-30$ & $287(\% 15.6)$ & $143(\% 49.8)$ & $144(\% 50.1)$ \\
$31-45$ & $463(\% 25.3)$ & $212(\% 45.7)$ & $251(\% 54.2)$ \\
$46-60$ & $609(\% 33.3)$ & $235(38.5)$ & $374(\% 61.4)$ \\
$61-95$ & $470(\% 25.6)$ & $140(\% 29.7)$ & $330(\% 70.2)$ \\
Histoloji & & & \\
Nonatrofik gastrit & $1410(\% 77.0)$ & $624(\% 47.8)$ & $736(\% 52.2)$ \\
Atrofik gastrit & $27(\% 1.5)$ & $11(\% 40.7)$ & $16(\% 59.3)$ \\
İntestinal metaplazi & $81(\% 4.4)$ & $18(\% 27.0)$ & $63(\% 73.0)$ \\
Malignite & $27(\% 1.5)$ & $5(\% 18.5)$ & $22(\% 81.5)$ \\
Normal & $284(\% 15.5)$ & $17(\% 6.1)$ & $267(\% 93.9)$ \\
\hline
\end{tabular}

\section{Tartışma ve Sonuç}

Gastrointestinal endoskopi, gastrointestinal hastalıkların ve $H$. pylori infeksiyonun tanisinda yaygin olarak kullanılmaktadır(9). Bununla birlikte Maastricht III konsensus raporu persistan dispepsi sikayeti olan 45 yaş altındaki hastalarda "test ve tedavi "' stratejisini yani non invazif H.pylori testi yapılıp tedavi verilmesini ilk seçenek olarak önermektedir (11). Günümüzde $H$. pylori infeksiyonunun tespitinde kullanılan çeşitli tanısal metotlar mevcuttur. $\mathrm{Bu}$ 
metotlar endoskopik gastrik mukoza biyopsisi gerektiren invaziv metotlar ve endoskopi gerektirmeyen noninvaziv metotlar olarak ikiye ayrılmaktadır. İnvaziv testler; kültür, histopatolojik test, hızlı üreaz testi ve PCR; noninvaziv testler ise ÜNT, serolojik testler ve HpDA'dan oluşmaktadır.(8,9). Noninvaziv testlerin geniş toplumlarda yaygın kullanımını k1sitlayan bazı dezavantajları mevcuttur. ÜNT ve HpDA testi ile aktif $H$. pylori infeksiyonunu tespit edebilirken, serolojik testler kişinin $H$. pylori infeksiyonu ile karşılaşmış olduğunu gösterir ancak. $H$. pylori'e karşı oluşan antikorlar eradikasyondan sonrada aylarca pozitif kalabildiğinden geçirilmiş veya aktif infeksiyon ayrımı yapılamaz $(8,9,12)$. ÜNT oldukça duyarlı, özgün ve tanısal doğruluğu yüksek bir noninvaziv testtir fakat pahalıdır, eğitimli personel ve kompleks cihazlar gerektirmektedir $(9,12)$. $H$. pylori infeksiyonunun tespiti ve eradikasyonun değerlendirilmesinde kullanılan HpDA; ucuz, kolay ve pratik bir testtir ancak duyarlılık ve özgüllüğü test kitinde kullanılan antikor tipine bağımlı olarak değişebilmektedir (13). İnvaziv yöntemlerden olan hızlı üreaz testi $\% 85$ 'in üzerinde duyarlılık ve $\% 95$ 'in üzerinde özgüllük değerlerine sahiptir (14). Mukoza biyopsi örneklerinin PCR ile incelenmesi maliyetinin yüksek olması ve uygulama koşullarının zorluğu nedeniyle bugün daha çok araştırmaya yönelik çalışmalarda kullanılan bir yöntemdir. Biyopsi örneklerinde, mide sıvısında ve dışkıda PCR ile $H$. pylori tespit edilebilmektedir. $\mathrm{Bu}$ yöntemin duyarlılığ1 ve özgüllüğü \%95 'in üzerindedir $(8,14)$. Kültür ve histopatolojik inceleme $\mathrm{H}$. pylori infeksiyonunun tansinda en iyi ve en değerli tanı yöntemlerindendir. Kültürün duyarlılığ1 \%70-95, özgüllüğ̈̈ ise $\% 100$ olarak bildirilmektedir.(8,9). Bizim çalışmamızda antrum-korpus biyopsisi alınan hastalarda $H$. pylori histopatolojik olarak incelendi. Ayrıca H. pylori varlığ 1 yanında yoğunluğu da incelendi.
Çalışmamızda endoskopi yapılan hastaların \%39.9'unda histopatolojik inceleme ile $H$. pylori infeksiyonu pozitif olarak tespit edildi. Literatürle uyumlu şekilde kadınlar ve erkekler arasındaki $H$. pylori siklığ 1 benzerdi $(15,16)$. Türkiye'nin değişik bölgelerinde ve değişik tarihlerde yapılan diğer çalışmalarda, H. pylori sıklığının \%4388,6 arasında tespit edildiği ve sıklığın bölge ve yaş gruplarında değişkenlik gösterdiği, son yıllarda yaşla birlikte azalma eğiliminde olduğu bildirilmektedir (6,7,17) Özardalı ve arkadaşları (18) 1998 yılında, Uyanıkoğlu ve arkadaşları (16) 2012 yılında gerçekleştirdikleri, Şanlıurfa yöresini kapsayan ve farklı endoskopik tanıları olan olguları içeren çalışmalarında; $H$. pylori pozitifliğini sirasiyla $\% 89.8$ ve $\% 71$ olarak bildirmiştir. Konakçı ve arkadaşları (15) 2010 yilında dispepsi şikayeti nedeniyle endoskopik biyopsi yapılan 218 hastanın $\% 50.5$ inde $H$. pylori pozitifliği saptamışlardır. Konya bölgesinde yapılan çalışmalarda; Kesli ve arkadaşları (19) 2010 y1lında dispepsi şikayetleriyle başvuran, endoskopik mide biyopsisi yapılan 168 hastanın \%36.6 da, Korkmaz ve arkadaşları (13) 2012 yılında endoskopi yapılan 198 dispepsili hastanın \%45.4 de H.pylori'yi pozitif olarak saptamışlardır. $\mathrm{Bu}$ sonuçlar bizim çalışmamızla uyumluluk göstermesine karşın İç Anadolu Bölgesinde yer alan yakın çevremizdeki diğer illerde ve Konya'da 2003-2008 yılları arasında yapılan çalışmalarda $H$. pylori antijen prevalans1; Sivas'ta \%70.1 (20), Konya'da $\% 64$ - \%44.2 $(21,22)$ ve Kayseri'de \%58.4 (23) olarak bildirilmiştir. Bu çalışmalar $H$. pylori sıklığının yıllara ve bölgelere göre değișiklik gösterdiği, batı toplumlarında ve Türkiye'nin batısında nispeten daha düşük olduğunu göstermektedir. H.pylori pozitifliği sıklığının bu çalışmalar ve bizim çalışmamızda farklı olması, çevresel nedenler, hijyen, düşük eğitim seviyesi, bölgesel geri kalmışlık, önceden gastrointestinal endoskopi yapılması ve 
daha az eradikasyon verilmesi gibi çeşitli risk faktörlerinin incelenen popülasyondaki mevcudiyetine bağl olabilir (1-3). Megraud ve arkadaşları ileri yaşlarda atrofik gastrit insidansının artmasiyla, $H$. pylori'nin ekolojik yuvasını kaybettiği ve sıklığının azaldığını göstermiştir (24). Histotopalojik incelemede, nonatrofik gastrit, atrofik gastrit, intestinal metaplazi ve normal histoloji gözlenen hastalarda $H$. pylori sıklığ 1 sirasiyla \%47.8, \% 40.7, \% 27.0, $\% 18.5$ ve \% 6.1 olarak saptandı. Açık ve arkadaşları yaptıkları çalışmada $H$. pylori sıklığı açısından yaş gurupları arasında anlamlı fark bulamamıştır (25). Bununla birlikte Uyanıkoğlu ve arkadaşları (16), 14-30 yaş gurubunda en yüksek ve 46-60 yaş gurupları arasında en düşük oranda $\mathrm{H}$. pylori saptanmakla birlikte aralarında istatistiksel anlamlı fark bulunamadığını bildirmiştir. Bizim çalışmamızda da benzer şekilde en yüksek $H$. pylori sıklığ1 14-30 yaş gurubunda gözlemekle birlikte bu çalışmalardan farklı olarak 45 yaş üstü hastalarda, 45 yaş altı hastalara göre $H$. pylori sıklığı istatistiksel olarak anlamlı derecede düşük saptand $1(\mathrm{p}=0.001)$. 14-30 yaş gurubunda $H$. pylori sıklığının daha yüksek olması bu yaş gurubunda daha az eradikasyon tedavisi uygulanması ve 45 yaş üstü hasta gurubunda atrofik gastrit insidansının artmasından kaynaklanabilir. Konya bölgesinde üst GISS endoskopisi yapilan hastalardaki histolojik incelemede H. pylori sıklığ $\% 39,9$ olup cinsiyetler arasinda anlamlı fark yoktur. H. pylori sıklığı 45 yaş ve altındaki hastalarda istatistiksel olarak anlaml derecede yüksektir. $H$. Pylori sıklığının yüksek olduğu bölgelerde; persistan dispepsi sikayeti olan 45 yaş altındaki hastalarda "'test ve tedavi "' stratejisinin maliyet etkin olacağı düşünülmüştür.

\section{KAYNAKLAR}

1. Suerbaum, S. Michetti, P. (2002). Helicobacter pylori infection. N Engl J Med. 347(15):1175-86.

2. Lehours, P. Y1lmaz, O. (2007). Epidemiology of Helicobacter pylori infection. Helicobacter. 12(1):1-3

3. Yücel, T. Aygın, D. Sen, S. Yücel, O. (2008).The prevalence of Helicobacter pylori and related factors among university students in Turkey. Jpn $J$ Infect Dis. 61(3): 179-83.

4. Hestvik, E. Tylleskar, T. KadduMulindwa, DH, et al. (2010). Helicobacter pylori in apparently healthy children aged 0-12 years in urban Kampala, Uganda: a community-based cross sectional survey. BMC Gastroenterol. 10:62-6.

5. Tünger, Ö. (2008). Helicobacter pylori infesiyonları. Infeksiyon Dergisi. 22(1):107-15

6. Karaaslan, H. Bektaş, M. Soykan, İ. Bozkaya, H. Bahar, K. Özden, A. (2003). Türkiye'de gönüllü kan donörlerinde Helicobacter pylori seroprevalans1. Türk J Gastroenterol. 14(suppl 1):SBO3/1

7. Göral, V. Özdal, B. Kaplan, A. Şit, D. Danış, R. (2005). Diyarbakır ilinde Helicobacter pylori antikor prevalansı. Akademik Gastroenterol Derg. 5:47-50.

8. Granstrom, M. Lehours, P. Bengtsson, C. Mégraud, F. (2008). Diagnosis of Helicobacter pylori. Helicobacter. 13(1):7-12.

9. McNulty, C.A. Lehours, P. Mégraud, F. (2011). Diagnosis of Helicobacter pylori Infection. Helicobacter. 16(1):10-8.

10. Koneman, E.W. Allen, S.D. Janda, W.M. Schreckenberger, P.C. Winn, W.C. (2006). Color of Atlas and Textbook of diagnostic Microbiology. 6th ed. Philadeşphia: LüppincottRaven Publishers. 403-8.

11. Malfertheiner. P, Megraud. F, O'Morain, C. et al. (2007). Current 
concepts in the management of Helicobacter pylori infection: the Maastricht III Consensus Report. Gut. 56(6):772-12.

12. Vakil, N. Vaira, D. (2004). Noninvasive tests for the diagnosis of $H$. pylori infection. Rev Gastroenterol Disord. 4(1):1-6.

13. Korkmaz, H. Kesli, R. Karabağl1, P. Terzi, Y. (2013). Comparison of the diagnostic accuracy of five different stool antigen tests for the diagnosis of Helicobacter pylori infection. Helicobacter. 18(5):384-91.

14. Bytzer, P. Dahlerup, J.F. Eriksen, J.R. Jarbøl, D.E. Rosenstock, S. Wildt, S. (2011). Danish Society for Gastroenterology. Diagnosis and treatment of Helicobacter pylori infection. Dan Med Bull. 58(4):C4271.

15. Konakcı, N. Gülten, M. İbanoğlu, M.S. ve ark. (2010). Kronik Aktif Gastritli Olgularda Helicobacter Pylori Sıklığı. Uludağ Üni Tip Fak Derg. 36(1):7-10

16. Uyanıkoğlu, A. Coskun, M. Binici, D.N. ve ark. (2012). Endoskopi yapılan hastalarda Helicobacter pylori s1klığı. Dicle Med J. 39(29):197-200.

17. Bulut, M. Armağan, E. Kıyıcı, M. Balc1, V. Atar, N. Gürel, S. (2004). Acil Servise Epigastrik Ağrı Yakınmasıyla Başvuran Hastalarda Helicobacter Pylori Sıklığı ve Tanıda Kalitatif Serum Ig G Testinin Yeri. Uludă̆ Üni Tıp Fak Derg. 30(1):7-10.

18. Özardalı, H.İ. Bitiren, M. Nazlıgül, Y. Yilmaz, N. (1998). Șanlıurfa yöresinde noneroziv gastritlerde Helicobacter pylori sıklığı. Genel Tip Derg. 8(1):149-52

19. Kesli, R. Göktürk, H.S. Erbayrak, M. Karabağlı, P, Terzi, Y. (2010). Comparison of the diagnostic values of the 3 different stool antigen tests for the noninvasive diagnosis of Helicobacter pylori infection. J Investig Med. 58(8):982-6.

20. Alim, A. Ataş, A.D. Güneş, T. ve ark. (2004). Sivas ili merkezinde semptomatik ve asemptomatik yetişkin bireylerde Helicobacter pylori seroprevalansı. CÜ Tip Fak. Derg. 26:75-80

21. Kalem, F. Özdemir, M. Baysal, B. (2010). Investigation of the presence of Helicobacter pylori by different methods in patients with dispeptic complaints. Mikrobiyol Bult. 44:29-34.

22. Özdemir, M. Baykan, M. (2005). Dispeptik hastalarda $H$. pylori infeksiyonu tanısında $H$. pylori gaita antijeninin tanı değerinin incelenmesi. Genel Tip Derg . 15:65-70

23. Arslan, D. Tahan, F. Demir, F. Taşkın, İ. (2006). Erciyes Üniversitesi Tip Fakültesi Çocuk Polikliniğine başvuran sağlıklı çocuklarda Helicobacter pylori enfeksiyonunun seroprevalans1 ve bunu etkileyen faktörler. Erciyes Tip Derg. 28:192-6.

24. Megraud, F. (1993). Epidemiology of Helicobacter pylori infection: Helicobacter pylori. Gastroenterology Clin Nort America. 22(1):73-88.

25. Açık, Y. Gülbayrak, C. Dönder, E. Yalnız, M. (2003). Firat tıp merkezine dispeptik yakınmalarla başvuran hastalarda Helicobacter pylori siklığ ve etkileyen faktörler. O.M. $\ddot{U}$. Tip Dergisi. 20(1):82-8 